\title{
Textbook Journalism? \\ Objectivity, Education and the Professionalization of Sports Reporting
}

\section{Introduction}

The two keys to success as a sportswriter are: (1) A blind willingness to believe anything you're told by the coaches, flacks, hustlers, and other 'official spokesmen' for the team-owners who provide the free booze ... and: (2) A Roget's Thesaurus, in order to avoid using the same verbs and adjectives twice in the same paragraph. (Thompson, 1973)

Ask a leading sports journalist to sum up their virtues and they would be indistinguishable from those of any other journalist: a deep, abiding love or fascination for their subject, a faith in their capacity to discern right from wrong, a hunter-gatherer's reluctance to throw away newspapers, magazines, books and matchday programmes, and an amply stocked, regularly replenished contacts book. (Steen, 2015: 14)

The disdain with which Hunter S. Thompson laid to waste American sports writing of the 1960s and 1970s, in a manner he mostly reserved for journalism at large, is extreme only in degree rather than kind. Sports journalism has long been the object of derision from within journalism, where it has been dismissed as the 'sandbox' or 'toy department' of the newsroom (Rowe, 2007). Sports journalism has been similarly ridiculed from within sport, where athletes and coaches have persistently doubted the qualifications of those who wield pens and prose to render athletic labour and culture (Toney, 2013). Yet, Thompson's typically scathing critique of sports journalism was somewhat merited. Reporters of this era were often financially supported - including the 'free booze' Thompson mentions and other payolas and freebies - by the same teams they were covering: a system that newspaper editors and owners were often happy to let persist so long as it led to cheap, consistent copy. This complicity led Thompson (1973) to reflect that 'with rare exceptions, sportswriters are a kind of rude and brainless subculture of fascist drunks whose only real function is to publicize and sell whatever the sports editor send them out to cover'. That some of his friends were sportswriters, as attested later in the same essay, was merely a case of exceptions proving the rule.

What has changed in the more than 50 years since Thompson's own writing heyday? Enough, in the estimation of sports journalist and senior lecturer at the University of Brighton Rob Steen (2015), to suggest that 'sports desks, once derided, slimly populated and barely tolerated, are now dignified all right, grudgingly valued' (p. 5) in the news- room. Two factors, or forces, appear as most 
significant in the professionalization of sports reporting. First, perhaps foremost, the money generated through sports content in an industry that is increasingly reliant on advertising revenue revenue generated in large part now by attracting hits and clicks from targeted 'digital audiences' ensures stable and lucrative content for editors who must react to the shifting economies and manifold platforms of contemporary news media. While sport has long afforded editors a steady stream of income, based on a prefigured calendar of events with national cul- tural resonance, some scholars and journalists have gone so far as to argue that 'sports journalism has moved from the toy department to the finance department', where 'it is now seen as crucial to the incomes and audiences of many media organizations' (Farrington et al., 2012: 1). Evidence supporting this claim about the increased impor- tance of sports journalism includes the rapid growth in the amount of coverage afforded to sport in British newspapers, such as The Times and The Guardian, which has nearly doubled between the 1970s and early 21 st century (Boyle, 2006).

Second, the training of journalists has become increasingly formalized. Journalism once required secondary-school qualifications only - with the assumption that through long hours of on-the-job training journalists would hone their writing and observational skills while developing strong sources and connections. Today's reporters are increasingly university graduates, trained in journalism schools or drawing skills from other degree programmes and scholarly fields (Frith and Meech, 2007). In keeping with this trend, dedicated degree programmes, such as Pennsylvania State University's Honours degree and the University of Brighton's Bachelor of Arts (Hons) Sports Journalism course, now prepare aspirants for the multimedia challenges of 21st-century reportage. Writing from Pennsylvania State's Department of Journalism, Marie Hardin et al. (2006) observed this correlation when suggesting that 'as sports media have grown, so have collegiate pro- grams and classes to train sports journalists' (p. 429). Moreover, and although this is a matter that relies on some slippery criteria into which we will soon delve, some have sug- gested that the quality of writing in sports reporting has improved over recent decades. James Toney (2013) goes so far as to propose that 'the best writing in any newspaper can frequently be found on the sports pages' (p. 89). Of course, the caveat that Toney is him- self a veteran of the sports beat might arouse scepticism among those for whom objectiv- ity is a keystone principle for assessing, as well as practising, the journalistic craft.

This article is a response to the apparent professionalization of sports journalism and, in particular, the formal education of sports journalists. Our specific concern is with how tomorrow's would-be sports journalists might learn to report on serious matters such as racism, corruption, environmental degradation and other issues identified as besetting sports media, amid this advancing professionalism. This is not to suggest that because of the professionalization of sports journalism, 
sport is only now implicated in such matters and requiring of commensurately 'serious' reportage. On the contrary, a large body of knowledge assembled by sport media scholars spanning some 50years illustrates the complicity of sport and sports journalism in all manner of societal ills (Weedon, Wilson, Yoon and Lawson, 2016), from jingoism (Maguire et al., 1999) and sexism (Pederson et al., 2003) to war-mongering (Silk, 2012). Even Hunter S. Thompson acknowledged that sports writing is more than a mirror onto its writers. 'There is a dangerous kind of sim- ple-minded Power/Precision worship at the root of the massive fascination with pro foot- ball in [the United States]', he wrote in the same 1973 post-Super Bowl issue of Rolling Stone magazine cited in our epigraph: 'and sportswriters are mainly responsible for it'. Whatever the measure of the influence of sports journalism - 'mainly responsible' is surely an exaggeration - this notion that media content is a kind of public pedagogy is among the most foundational arguments for taking sports and sports journalism seriously as objects of scholarly inquiry (Donnelly, 2011).

In this spirit, our study asks how a new generation of sports journalists might come to address the kinds of issues that concern journalists, sports media scholars and many in the public at large. We focus our analysis on a specific symptom of this professionalism: a genre of sports journalism textbooks, field manuals, and how-to guides, authored by current and former sports journalists and written to convey the craft of sports writing. We suggest that these books are at once expressions of the shifting political economy of journalism and news media, and engines for educating a new generation of sports journalists. They can also be seen as part of a movement towards professionalizing and legitimating sports journalism: for achieving acceptance from peers within the journalism profession, and distinction from 'pretenders' beyond the sports desk. In turn, these books represent the 'expansion of sports journalism' observed by sports media scholar Raymond Boyle (2006) - an expansion that 'offers challenges to both critics and educators involved not only in teaching about journal- ism but in critically evaluating its wider cultural, social and political impact' (p. 2). Viewed this way, the emergence of these books en masse may say as much about changes surround- ing the sports journalism profession as the contentions made within them.

A premise of our approach is that the matter of 'what one needs to know and do' in order to be an excellent sports journalist is best broached as an open and important ques- tion. For as with journalism at large, what constitutes quality sports reporting is far from settled, and the presumption of consensus on this matter does not service the aims of either sports journalists or academics interested in sports media (Post, 2015). In pursuing this question, we incite a series of long-standing controversies that structure the essay to follow. To begin with, we confront a 'journalistic exceptionalism' that renders the involvement of academic (in our case, social science-based) commentators and research- ers - who specialize in some way in the study of sports media, and at 
times offer observa- tions and even recommendations pertaining to the practice of reporting - as suspect and unhelpful. This exceptionalism, rooted in a long-standing theory-practice division that prevails in many crafts, has been accentuated by the ostensible triviality of sport as jour- nalistic (or scholarly) subject matter.

In outlining our methods, we then broach a second controversy concerning why we would focus on textbooks to address questions of journalistic practice. The apparent remove of textbooks from the 'doing' of sports journalism might make these books, and our analysis by implication, especially suspect among those who would describe journal- ism as a field of inquiry that is habituated in practice, and therefore a profession only knowable from within. This is our opportunity to reflect on what these textbooks can tell us - as well as what they cannot - about how sports journalists have and might in the future address socially and ethically sensitive matters.

In the remainder of the essay, we report on a thematic analysis of sports journalism textbooks. This analysis includes an examination of the concepts, tropes and anecdotes that are invoked to instruct readers - assumedly current and aspiring reporters - on 'qual- ity' sports reporting. We detail how objectivity and ethics are the primary points of recourse through which these books advise on reporting about the many social issues in which sport is implicated and reflect on the virtues and shortcomings of these advoca- tions. In doing so, we retain a focus on both the content and the context of these books, which we might think of as technologies of professionalization: intended to distinguish the good and bad of sports reporting while also forming, through their collective emergence, a distinctive canon on the question of 'quality' journalism.

\section{Journalistic exceptionalism I: 'Quality' and sport reporting}

Our point of entry for this analysis - as sports media researchers - raises a central point of contention in debates around journalistic quality. Despite journalists, at least in the United Kingdom, increasingly holding university educations over the past three decades (Frith and Meech, 2007), there remains a suspicion about the ability of those who are not journalists - especially academics - to offer valuable commentary on the practice of journalism. It would seem that the spectrum of scepticism moves from an indifference or neglect of, say, sociological perspectives at one end to outright hostility at the other. As an example of the latter, take the view of Roger Scruton, as cited in the Guardian Media Guide:

Media studies course content is sub-Marxist gobbledegook and courses are taught by talentless individuals who can't get jobs in the media, so they teach instead. There's nothing really to learn 
except by way of apprenticeship on the job. (Fisher and Peak, 1998: 306, cited in Frith and Meech, 2007: 140-141).

It bears emphasis here that media studies and journalism schools are not interchange- able nor uniformly different. However, that is clearly not the point of this passage. Scruton's overriding message, to which we will return later, is that what is learnt 'on the job' as a journalist is all that one needs to know. The rest is filler, 'sub-Marxist gobble- degook' even. The prevailing contention here is that one can only glean privileged knowledge about journalism in practice, through the journalistic beat. As Frith and Meech (2007) reflected, 'it's difficult to think of another field (not even education) in which practitioners believe that the study of what they do is irrelevant to their practice' (p. 141). Taking this exceptionalism at its word leads to an epistemological conundrum: If we can only know journalism from within, then can it only be evaluated by those who are schooled in the craft? And what does this reluctance to accept the possibility of evalu- ation from without mean when journalists themselves call for the independent evaluation and accountability of other institutions, such as governments and corporations, or ger- manely for our study, Fédération Internationale de Football Association (IO) and the International Olympic Committee (IOC)?

In raising these questions, we join in debates around what constitutes or 'counts' as excellent reporting that are ongoing within and around the journalism profession. Media scholars such as Robert McChesney (2013) and Justin Lewis (2014) have recently argued that while such discussions have perennially surrounded the role of media in democratic societies, the present moment demands an intensified and deepened engagement with questions about quality journalism and the concerns that inspire them. Of particular rel- evance here are long-standing concerns about the increasing corporatization and cen- tralization of mainstream media ownership - and especially about the influence of profit motives on the types of news stories that are offered to the public. A lack of diverse perspectives offered by journalists on key issues, and decreased funding and support for indepth investigative reporting that sometimes threatens the establishment and compro- mises the interests of advertisers are also significant. An additional, emerging concern is that established models of revenue generation for major news outlets are becoming less viable, leading to a situation where individual stories are increasingly assessed according to the number of 'hits' they receive in online formats, and not according to the reputation of news outlets more generally, or standards of journalistic excellence (McChesney, 2013). Taken together, these factors and others are seen to undermine attempts to uphold any kind of agreed-upon standard for excellence in reporting (Lewis, 2014).

Faced with these factors, some scholars and journalists have devised and promoted strategies for 
improving and even standardizing journalism. Such strategies include the development of a range of models of 'excellent' or 'best practice' journalism, including civic journalism (Rosen, 2001), deliberative journalism (Romano, 2010), peace journal- ism (Lynch and McGoldrick, 2005) and development journalism (Thussu, 2000). While each of these models is based on somewhat unique understandings of the role of the journalist - and are underpinned in some cases by distinct theoretical viewpoints - what they collectively offer is a sort of practical guide for journalists interested in better align- ing their work with a particular conception of 'excellence'.

That sports journalism has not been featured in these discussions should not be sur- prising. David Rowe (2007) has described how infantilizing monikers such as 'toy department' and 'sandbox' betray patronizing attitudes towards sport and sports report- ing - noting also that there is 'a surreptitious ideology here (the assumption that toys and play are not serious and important) that derives both from traditional, class-based and patriarchal perspectives on the press and popular culture in general' (Croteau and Hoynes, 2003; Hartley, 1996) and on sport in particular (Rowe, 2007: 386; Tomlinson, 1999, 2005). Sports journalism's long-standing reputation as the 'toy department' or 'sandbox' of the newsroom therefore goes some way to explaining its absence in discus- sions of quality.

Nevertheless, the evidence compiled by many of those who have studied sports journalism and sport media would suggest that such discussions would be timely, if not belated. For some 50 years, a body of critical scholarship has shown sports media to perpetuate inequality along intersecting axes of gender, race, nationality, sexuality and dis(ability) through heteronormative, patriarchal, xenophobic and otherwise dis- tressing coverage (authors, 2016). At the same time, print and broadcast media have also been shown to be complicit in generating consent for war and military interven- tion (Silk, 2012). That these issues have been continually identified in sports cover- age over several decades might have animated Rowe's (2007) frustrations when he wrote that

an unprecedented opportunity to diversify and deepen [sports journalism's] remit occasioned by its expansion and heightened cultural resonance is seemingly being squandered by an excessively close integration with the sports industry, a lack of critical ambition, and an unimaginative reliance on socially and politically de-contextualized preview, description, and retrospection regarding sports events. (p. 400)

Notwithstanding Rowe's concerns, with which we agree, advancing professionaliza- tion in sports journalism might also help to animate a progressive conversation about the overall quality of sports media. Many sports media scholars would argue that it is high time that sports journalism itself be 
placed under the same scrutiny as the rest of the fourth estate.

Nevertheless, and despite decades of critical scholarship on sports media and journal- ism, the place of academics - especially those without experience as journalists - in debates about improving the quality of sports journalism remains a source of potential controversy. The afore-cited critique of media studies expressed by Scruton is, according to Frith and Meech (2007), less an anomaly or lonely outlier than it is a pronounced articulation of a widely held scepticism towards 'outsiders' whose knowledge is expressed as abstraction, rooted in a long-standing binary between theory and practice. Such philosophical arguments are not for rehearsing here without space to do the necessary grounding work, yet the effects of this viewpoint are certainly relevant to thinking about relationships between journalistic education and newsroom culture, between class- rooms and news beats, and between theoretical and practical knowledge. Although our study of textbooks does not address these relationships directly, these issues are of course relevant to the analysis we undertake here and the claims we make about the implications of 'textbook journalism'.

\section{Journalistic exceptionalism II: Education and textbooks}

A second and related controversy associated with our approach pertains to its focus on textbooks. We identify this as a controversy because if classroom education in universi- ties is deemed to be at too great a distance from journalistic practice to be of conse- quence, then textbooks about doing journalism are surely at some stratospheric remove from the reality of the beat. Perhaps we can see this view of textbooks as one of the reasons why, as Hardin et al. (2006) observed, 'few studies have addressed the messages about diversity in texts for journalism students, and [why] none', until Hardin et al.'s own study, 'has examined sports journalism texts' (p. 434). Hardin et al.'s study outlines how male hegemony is reproduced in sports journalism textbooks through the predomi- nant referencing of male authors and through the over-representation of male athletes and journalists. In doing so, Hardin et al. offer great insight into how textbooks are encoded with broader social and cultural norms. These textbooks, they state, 'reinforce the idea that sports and sports journalism are masculine; they are enterprises for men' (p. 441). While there is a history of textbooks being subject to critical analysis, especially in educational studies and related fields (Hardin and Hardin, 2004), Hardin et al.'s study - albeit one with a focus on men and masculinity - represents a valuable precedent for our own research.

Nevertheless, questions remain about the relationship between sports journalism text- books and sports journalism as it is practised. To state the obvious, textbooks are not mirrors on journalistic practice. It would be equally naive, though, to accept that text- book sports journalism and sports 
journalism practice represent unrelated worlds: one a place of classroom theories, hypotheticals and abstraction; the other a world of exclusive 'insider knowledge' and habituated practice. The relationship between textbooks and practice is especially germane for our study because the texts we analysed are in most cases authored by current or former sports journalists and therefore draw on years of journalistic experience.

As Shapiro (2010) noted in his research on journalistic standards more broadly, the question of connections between the study and theory of journalism and journalistic practice is directly related to questions of journalistic excellence. He observed that 'jour- nalists, scholars of journalism, and others with interest in the field lack a common evalu- ative lexicon. This hermeneutic gap between theory and practice cannot but make a difference to quality in practice' (p. 145). In this same spirit, and to reiterate, our concern is with the repercussions of leaving sports journalism to adjudicate its own criteria for excellence, especially coverage of socially and ethically sensitive matters in which sport is implicated. How are we to broach this problem in order to understand what we are reading when we read sports journalism textbooks?

As outlined in our introduction, we suggest that these textbooks on sports journalism both reflect and produce the practice of covering sports. That is to say, they are at once reflective of - indeed, directly informed by - the biographies and experiences of the cur- rent or former sport journalists and sports journalism educators who author them and generative of efforts to educate would-be sports journalists on the practice of covering sport. In other words, many decades of journalistic experience are folded into these texts. They convey a rich and textured version of what best practice journalism is and should be, as they are the collective sum of many years spent covering sport on the journalistic beat, and in some cases of teaching sports journalism students.

The character of the connection between textbooks and practice, of course, is still not easy to decipher or to premise in advance. On one hand, Hardin et al. (2006) argue that 'textbooks are considered a powerful part of the educational process; students see texts as truth' (p. 430). On the other hand, textbooks are unlikely to be read in isolation, and questions about how lecturers and students in sports journalism programmes might adhere to, interpret, translate or disregard the contents of textbooks are not revealed through an analysis of the texts themselves. More speculatively, the notion that sports journalists of tomorrow will be drawn from these undergraduate programmes - and that those who are will apply the skills developed in these programmes across the same multimedia platforms - is far from assured, given the changing landscape of media institutions and communications. And there is also the broader question of socialization, whereby course-based and/or textbook-driven instruction about the pitfalls of, say, hegemonic masculinity or ableist 
coverage will compete with a range of other sedimen- tations and reinforcements of the prevailing social order that also take shape within and beyond the classrooms of journalism schools. Broader questions of knowledge transla- tion from textbooks and classrooms to coverage must, therefore, wait for another pro- ject. In any case, sports journalism textbooks, manuals and guides represent the most readily available account of the 'doing' of sports journalism, at least from an educa- tional perspective.

\section{Which books? Our sample and procedures}

While textbooks on sports writing date back to at least Garrison's (1993) Sports Reporting and Fink's (1995) Sportswriting: The Lively Game, we have selected books published in the 10years preceding our analysis (2005-2015). Given the multimedia developments and political-economic changes in journalism as practice and industry during this time, we opted for a sample which would most likely be reflective of contemporary sports journalism and be in current classroom use.

In total, we sampled eight books, each authored for an audience of would-be sports journalists and selected on that basis. In ascending order of publication, our analysis comprises the following:

- Sports Journalism: A Practical Introduction (Phil Andrews, 2014 [2005]);

- Sports Media: Reporting, Producing, Planning (Brad Schultz, 2005);

- The Essentials of Sports Reporting and Writing (Scott Reinardy and Wayne Wanta, 2015 [2008]);

- Sports Journalism: A Multimedia Primer (Rob Steen, 2015 [2008]);

- Sports Journalism: An Introduction to Reporting and Writing (Kathryn T. Stofer, James R. Schaffer, Brian A. Rosenthal, 2010);

- Field Guide to Covering Sports (Joe Gisondi, 2011);

- Race, Racism and Sports Journalism (Neil Farrington, Daniel Kilvington, John Price and Amir Saeed, 2012);

- Sports Journalism: The Inside Track (James Toney, 2013). 
These books are mostly authored by current or former sports journalists who now hold faculty positions in British and North American universities. For example, Joe Gisondi, author of Field Guide to Covering Sports (2011), worked as a journalist and editor for 20 years in Florida before taking up a post at East Illinois University teaching courses on sports writing, editing and media. Other books are collaborations between faculty and current sports journalists, such as Kathryn Stofer, James Schaffer and Brian Rosenthal's Sports Journalism: An Introduction to Reporting and Writing (2005).

While the entirety of each book was intended to convey 'best practice' - this is in principle their raison d'etre - we were especially attendant in our reading to instances where social, political and ethical matters were explicitly referenced. We were interested in themes that serendipitously emerged during our reading of the books at the same time that we attended specifically to questions of 'best practice' with respect to the areas out- lined above - which is to say, the analysis was both inductive and theoretically driven (Braun and Clarke, 2006; Bryman, 2012). Our study is therefore not a content analysis as there is not a consensus on any criteria as to what constitutes 'excellence' or 'best prac- tice' journalism to structure such an approach. Nor was it conducted by detached, neutral onlookers. Without any formal experience as journalists, we approached each book with an ethnographic sensibility, that is, as a window onto the priorities and practices of sports journalists. Our analysis, in turn, is informed by our shared, sustained interest in the bet- terment of sports journalism - and with a particular interest in and sensitivity to how social, political and ethical matters are understood and conveyed with respect to 'advice' for coverage. It is also reflective of our own positions writing from within Anglo- American institutions insofar as the books we have chosen, and the sports and sports journalism that they engage, are written in English. Just as our discussion of journalistic objectivity to come warns against universalizing sports coverage, we acknowledge that our claims about these books do not, or at least may not, translate beyond their shared context.

\section{Thematic analysis}

In summary, the main findings that emerged from our analysis were that (a) advice about how to cover sport-related social issues was expressed mostly in relation to 'objectivity' - a concept that was highlighted near the beginning of most of the books, and (b) that discussions of more nuanced ethical and social issues that underlay coverage of sports were less prominently featured and were surprisingly brief and underdeveloped (with key exceptions) - while appearing most often near the back of the books and sometimes in appendices. Mirroring the structure of (most of) the books, we begin by reviewing how objectivity is invoked therein, and how this concept has been equated with 'quality' sports reporting. 


\section{The road to objectivity (or 'no cheering in the pressbox')}

In opening his Field Guide to Covering Sports, Joe Gisondi emphasizes that 'being objective' is a defining characteristic of the sports journalist. Gisondi's point is made through recourse to a wellworn trope about press box etiquette. 'Cheering', we learn - or indeed any visible or audible manifestation that betrays one's investment in the outcome of a sporting contest - is to be stifled by the would-be reporter. As Gisondi (2011) puts it,

Cheering clouds perspective, preventing a sports reporter from discerning the plays, trends or strategies that enabled a team to win. In addition, you could lose some sources who might refrain from speaking with someone willing to spin everything for the home team. (p. 2)

It is not entirely clear whether cheering itself is the problem - that is, whether the emotions that come with cheering will 'cloud' the mind, as in the Cartesian model of mind over body - or whether displaying the affinities that incite cheering is the problem. Put another way, do sports journalists need to disavow their passions for sports and particular teams and athletes or just stifle them in the name of professional etiquette? In any case, it seems that it is the potential effect of cheering - the loss of sources or respect of one's peers - that is of greatest concern.

As an initial observation, this immediate appeal to keeping your sources happy lends weight to Rowe's (2007) critique of sports journalism as a beat that 'seeks reinforcement and affirmation from the largely closed circle of sources that creates the insular world of sport in the first place' (p. 400). No doubt, and as many of the books we consulted attest, the balance between keeping sources close and the competitive demands of garnering readerships and breaking stories is fraught and often whether recognized as such or not - a matter of ethics. Hence, Brad Schultz's (2005) claim that 'the opposite side of homerism [i.e., siding with the home team] is criticism, or the sports journalist as provocateur. While homers try to sympathize with the audience, critics are purpose- fully negative' (p. 25).

As is evidenced by this binary, a significant limitation of these books is that the concept of objectivity is mostly confined to the internal logic of the sporting contest. But before rushing to any judgement, it is important to reflect on why any notion of objectivity would be presented as a touchstone principle for the aspiring sports reporter in the first place. To do this, we looked especially to journalism scholar Stephen Ward (2004), who explains how the 'doctrine of objectivity' was invented by newspapers in the early 20th century in order to 'assure the public that its news was factual and fair' (p. 10). While recourse to objectivity as an ethical norm can be dated 
back as far as ancient Greece and although ethics has been a broad consideration for news reporting since the invention of the printing press, objectivity entered the lexicon of journalism during this era as part of broader debates about media and democracy.

A central figure in these discussions was American journalist and social commentator Walter Lippmann, who famously argued in his 1922 book Public Opinion that demo- cratic society requires non-partisan information in order to function, and that some degree of objectivity among those employed by the Fourth Estate is necessary for an informed public. Lippmann's adversary on this issue at the time, philosopher John Dewey, rejected the suggestion that a uniform journalistic stance on matters of public import equated to democracy, and instead argued for a diverse range of perspectives in the press that 'take a stand' on key issues.

Such debates have mostly been seen as irrelevant to sports reporting - or so it would seem from our read of these textbooks - for reasons that are perhaps reflective of the 'toy department' moniker. What does it matter whether what is said about sports is fair, accu-rate, balanced or in accordance with agreed-upon procedure, when the whole cultural phenomenon is extraneous to the serious matters that concern 'proper' journalists and concerned citizens? Rob Steen (2015) identifies with this escapism to some degree when remarking that '[f]or all those regular intrusions by harsh, unforgiving reality, sports journalism is still for the juvenile at heart, the fun-lovers and the thrillseekers, the romantics and the idealists' (p. 9). What's more, Steen questions whether it is possible, let alone preferable, to practice objectivity when covering sports, writing that '[f]or all the impartiality it requires, this is no more a job you can do dispassionately than you can do blindfold' (p. 10). 'Besides', he adds, 'no newspaper or magazine editor I know would hire anyone ... who did not have the wherewithal to be one-eyed' (p. 10). In addition to the importance clearly placed on alluring sports writing in this passage, we might infer here that there is a shared understanding among many sports journalists - and perhaps now among students of sports journalism - that literary style and objective principles are not always compatible.

Objectivity is taken up in different ways across the books, mostly manifesting either as the insistence on impartiality as a defining trait of the sports reporter (as in Gisondi), or as in Steen's suggestion that 'taking a stance' is in fact what editors want because it often makes for provocative copy. Sport, after all, is organized around partisanship, with national and cultural identity often projected onto sporting contests. What's more, the naïve idea of objectivity as detachment, distance and feigned disinterest has been challenged both in journalism (see Ward, 2004, on 'pragmatic objectivity') and in the philosophical and scientific circles from which it is derived (see Harding, 2015, on objectivity and diversity, for a recent contribution to an ancient debate). Why, then, at this moment, is 
objectivity a point of debate in sports journalism schools (Steen acknowledges the debate as ongoing in the University of Brighton's Sport Journalism programme) and beyond?

We venture here to suggest that objectivity is enlisted in these books as a journalistic rite of passage. The point is not so much that a journalist can, should or must be 'neu- tral' in their coverage of sports - deploying rigid criteria that censors the senses or prises apart facts from values. Rather, the point is that the capacity and responsibility to 'be objective' is what distinguishes sports reporters, and journalism, from sports fans and supporters. By highlighting their professional mandate to be objective, sports journal- ists can distinguish themselves from the cacophony of competing views from online forums and phone-ins to fan TV and the Twittersphere - thus allowing these writers to continue lay claim to an authoritative status within multimedia circuits of communication.

\section{'Telling it like it is'}

This observation about objectivity and authority leads to another - one that more specifi- cally addresses our interest in coverage of social issues. As noted earlier, where objectiv- ity is raised in these books as a principle of journalistic inquiry, it is mostly done in regard to the internal logic of sports. As a sporting spectacle is contained in space and time, and the terms of the contest prefigured in advance, this seems to lend itself to a style of coverage that Stephen Ward called 'ontological objectivity' - meaning 'telling it like it is', and so implying a singular state of affairs about which one is reporting. The threat to objectivity is that 'subjective' behaviour will betray affiliations with and prefer- ences for a particular sports team, athlete or region, and so compromise the credibility of the journalist as a trusted authority on sporting matters. This question of authority is the point on which debates about objectivity seem to hinge. Thus, after echoing Gisondi's sentiments on press box etiquette - 'A front row seat, but keep ya trap shut' - Stofer et al. (2010) write that 'a sportswriter doesn't have to be completely neutral either ... writ- ers should avoid taking a hometown angle, unless they're writing a column, and even then they should try to be as even-handed as possible' (p. 17). Similarly, when Scott Reinardy and Wayne Wanta (2015) invoke objectivity in The Essentials of Sports Reporting and Writing, it is in relation to the problem of 'homerism' in sports columns (p. 201). In their words,

[A] sports columnist ... must spend a great deal of time getting to know the key sports figures in an area. This can sometimes cause reporters to get too cozy with the sports figures, making them lose sight of their objectivity. (p. 201)

And yet, these comments are preceded by the assertion that '[c]olumnists are sup- posed to take a 
stand. It doesn't matter if they are right or wrong. What matters is that the columnist makes a cogent point and backs it [sic] with solid evidence' (p. 197). The ten- sion is perhaps best summarized by Rob Steen (2015), when he contends that '[b]alanc- ing objective reporting with local loyalty, the expectations of your readers and editor, and the need to maintain a working relationship with clubs and officials with whom you may have daily contact is as difficult as journalism gets' (p. 16). The appeal of opinion-driven narratives and angles of inquiry versus the principle of factual, unbiased sports reporting: this is the extent to which objectivity is debated across these books.

Without wanting to draw any strict lines between sports reporting and social issues, the internal logic of objectivity does not satisfy the concerns of many sports media schol- ars. These folks, ourselves included, take an interest in sports journalism principally because sports transcend the sporting contest, and any notion of objectivity cannot - or should not - be confined to on-field matters. Hence, sports media research - as conducted by critical sociologists, media studies and communications studies scholars, and others interested in what is sometimes known as the sportmedia complex (see Jhally, 1984 and many others since) - has predominantly focused on instances when sports coverage perpetuates social ills, such as the under-representation, trivialization and sexualization of female athletes and women's sport; heteronormative assumptions about sport and stigmatization of non-conformist expressions of sexuality; xenophobic, jingoistic and 'us'/'them' divisions; consent and support to military action based on national, colonial and related affiliations; and the heightening of fears around national security through sensationalist reporting. Of course, there are many points of crossover between issues 'within' and 'outside' of sport - such as when athletes facing criminal charges are or are not suspended from play, or when corrupt governance affects sporting results (issues which several of the books do mention in differing contexts). But never- theless, it seems that the kind of objectivity that is said to distinguish fans from journal- ists, and that is intended to keep match reports and columns clean of bias, is qualitatively different from that invoked by sports media scholars concerned with social and political issues. To see where these 'sports journalists turned authors and pedagogues' often locate the crossover, and to seek out where and how would-be sports journalists are instructed on the kinds of matters listed above, we must turn to the category of ethics, from which notions of objectivity are often derived.

\section{Relegated to the back pages? Ethical codes of conduct}

Whereas discussions about the internal logic of objectivity in sports reporting take 'the lead' in most of the books we studied, matters of ethics are mostly located at the back. There is a certain irony here insofar as sports coverage has often been called the 'back of the book' (Toney, 2013) by the journalistic fraternity, for whom page order was a hierarchy, and sports were rightfully located at the 
bottom. In most - but not all - of these sports journalism textbooks, ethics are formally addressed as an appendix (Andrews, 2014: 169-170; Gisondi, 2011: 274-278; Stofer et al., 2010: 261-264; Toney, 2013: 143-145), or in one of the book's final chapters (Reinardy and Wanta, 2015: 261-278; Schultz, 2005: 213-228). Are ethics to sports journalists what sports journalism has been to their mainstream counterparts - necessary filler to prop up the more serious, substan- tive content?

There is an apparent logic to addressing ethics as an appendix: that being to reproduce a pre-existing Code of Ethics, such as the Society of Professional Journalists' Code of Ethics, the Code of Practice of the British Press Complaints Commission, or the Associated Press Sports Editors Ethical Guidelines. Most of the authors reproduce, and some then interpret these codes and guidelines as a checklist for readers, with headings such as 'Don't accept gifts' (Gisondi, 2011: 275) and selfchecking questions like 'Have I been honest about my sources, even if I can't name them?' (Andrews, 2015: 170). And among these there are some direct appeals to the kinds of issues that interest us as critical sports media scholars, such as Phil Andrews' suggestion that journalists ask of their con- tent: 'Does it display prejudice because of race, gender, age or disability?' (Andrews, 2015: 170). This ethical question stands out among a list of reflexive questions that advise abstaining from financial inducements and fostering strong relationships with sources, and the sentiment is certainly agreeable. But for those who have studied how 'race' (Wilson, 1997), gender (Cooky et al., 2015), age (Pike, 2011) and disability (Howe, 2008) are perennially portrayed in problematic ways in sports media, Andrews' state- ment reads as rather glib to the extent that there is little follow-up guidance on what displaying prejudice looks like and how portrayals of such issues and topics may subtly contribute to systemic forms of, for example, racism or sexism.

Elsewhere, we find caveats added to the same message. James Toney (2013) offers the following guidance in his Ethics Appendix:

Journalists should not use information about which they are privy for their own financial profit in advance of its publication and they also have a moral obligation to protect the confidentiality of their sources. Reporting should also never demonstrate prejudice or reinforce stereotypes with regards to race, gender, age, sexuality, or disability. Of course, there are always exceptions to the above, particularly when the newspaper is able to claim a defense of the public interest. For example, they may claim that secret recordings are the only way to detect or expose a crime or serious impropriety or they are preventing the public from being misled by an action or statement of an individual or organisation. (pp. 143-144)

It is unclear in this passage what demonstrating prejudice or reinforcing stereotypes looks like and when or how it would be in the public interest to make exceptions to this guideline. Perhaps there is 
some slippage here, as Toney comments mostly on his first point regarding the 'moral obligations' to protect one's sources. But the passage - and the book - nonetheless leave readers at best none-thewiser as to how and why to avoid prejudice and stereotyping. What's more, these declarations imply that instances of prej-udicial reporting are detectable by the individual journalist, and so can be refrained from, should they choose: a problematic assumption that we revisit in our conclusion.

One interpretation of the location of ethics at the 'back of the books' is that these checklists and Codes are an afterthought - acknowledged, yes, but appearing as tangen- tial to the conducting of interviews, the writing of match reports and other journalistic activities foregrounded in 'main body' chapters. But a closer reading of the books tells a slightly different story. Etymologically, ethics derives from the Ancient Greek ethikos, which in turn has its root in ethos, meaning habit, or custom. It is perhaps not surprising, then, that ethical matters are implicitly addressed within the full body of the texts as well as in their dedicated sections - in the sense that the habits of journalists (including those related to covering social issues) are commonly detailed by way of examples, practical suggestions and forewarning tales from the field.

For example, Brad Schultz (2005) cautions against 'social commentary' in an extended passage that demands our attention. After first decrying the home-team bias - again, the betrayal of objectivity and thus professionalism - as an increasingly fraught and undesira- ble approach to sports writing, Schultz (2005) turns his attention to 'social commentary':

Social commentary is another dangerous area for sports journalists. Such commentary usually goes beyond opinion and frames the story within the context of some important social issue, such as discrimination, race, or gender. For example, a social commentary on the (alleged) use of steroids by baseball players might not focus so much on what players are taking them, but rather on the larger issue of whether such enhancements are good for the game. Any issue that involves moral behavior is extremely difficult because the audience has so many definitions of morality. People generally do not like to be told what to think or believe, especially when it comes to sensitive issues involving personal habits or values. This is especially problematic in sports, which as we have seen is often characterized as less important than what's going on in the rest of society. There is a large segment of the audience that attaches no social significance to sports and simply wants to know who won, who lost, and what happened in the game. (pp. 26-27)

This passage is a red flag for critical sports media scholars. As with Toney's comments on prejudice and discrimination, the notion that the journalist 'frames the story' within the context of 'race, or gender', and that 'a large segment of the audience ... attaches no social significance to sport', implies that it is a matter of choice to either divorce sport from society, or for journalists to enter the 
'dangerous' terrain of their entanglements. One of the foundational premises of the sociology of sport, a field that has contributed a great deal to the study of sports media, is that sport and society are irrevocably connected and that it is the character of their relation which must be con- fronted and debated (Andrews and Giardina, 2008). Moreover, in order to contribute to a healthy democracy, it is often held that journalists must confront - not avoid - 'dangerous', controversial subject matter. Indeed, Rob Steen (2015) heralds this as his impetus to become a sportswriter in the 1980s. 'What ultimately motivated me', he wrote, 'was the absolute conviction that, as a cricket and rugby writer, I might help, in however miniscule, anonymous or invisible a way, to bring down apartheid and end all racism' (p. 10). Steen substantiates this point later when he proclaims that 'Being a columnist is not hugely unlike playing God' as you get to play 'judge, jury and bailiff’ (p. 151).

This presumably tongue-in-cheek aggrandizement aside, Steen's book does offer an analysis of how sports journalists have addressed socially sensitive issues - and does so in a uniquely direct and nuanced manner compared to most of the other texts we analysed. In a chapter entitled 'Me, the jury: Expressing yourself (responsibly)', he stages a discussion of how sportswriters in the British press responded to a controversy embroiling football governance and issues of 'race' and racism. The story centred on comments by the then-FIFA President Sepp Blatter, the gist of which being that 'there is no racism' in football (16 November 2011, cited in Steen, 2015: 151). Steen assembles an array of journalistic responses to Blatter from leading British newspapers, beginning with the vociferous writing of Steven Howard (The Sun), Henry Winter (Daily Telegraph) and Simon Barnes (The Times), whom each took the opportunity to lambast Blatter for 'crass stupidity' and for being an 'embarrassment to a wonderful sport', 'foolish', 'ridiculous', 'offensive' and more besides. This critical response in Steen's book, quite apart from the aversion to controversy advised by Schultz in his book, might resonate among critical media scholars.

But some matters are not so straightforward, and criticism is not necessarily the royal road to social justice. As Steen observed, some writers, such as Duleep Allirajah of The Independent, displayed a 'more highly attuned sense of proportion' than those who has- tened to denigrate Blatter. Without defending Blatter or his comments, Allirajah noted that 'England might be a declining football power, but we're world beaters when it comes to lecturing foreigners about their ethics' (2 November 2011, cited in Steen, 2015: 158).

Rather than take Blatter's comments as yet another opportunity to judiciously denounce the thenFIFA President, Allirajah widened the lens in noting that England's historically fraught relationship with FIFA, up to and including the English Football Association's failed bid to host the 2018 World Cup not so long before these comments were made, may be colouring the outraged response. Steen 
(2015) then cited the 'pertinent contex- tual point' (p. 158) made by James Lawton, also writing in The Independent, that had England won the rights to host that tournament, Blatter's comments may not have been met with the same hostility among the British press and public.

Whether Lawton is correct in his assessment is hard to say, and this is not the crucial point at stake here. In Sports Journalism: A Multimedia Primer, Steen walks the reader through journalistic responses from Britain's leading newspapers to a story about racism and, without committing himself to any template for best practice or heralding absolute rights and wrongs, highlights the virtues of historically, politically and culturally informed sports reporting. The reporting that focused on Blatter's views was, as Steen points out, not exactly lacking in context. Rather, the coverage tended to emphasize Blatter's own long list of misdemeanours and unreconstructed prejudice, often framing him as a man out of touch with a fraught multicultural present - while at the same time betraying the residue of British exceptionalism. What distinguished the writing with which Steen found favour was its reflexive deployment of context - its acknowledgement of Britain's own complex position when it comes to denigrating others for discrimination in football, both in terms of its historical complicity in colonial football governance and more recent examples of political dealings between England's Football Association and FIFA. Keen readers of Steen's book might pick up on this and take heed; others might be left curious as to why Britain's colonial past is at all relevant to goings-on at FIFA's Swiss headquarters.

\section{'Race', journalist integrity and objectivity}

A final example of how ethics is treated in these books also illustrates one of our major claims about these books: that texts designed to inform the craft of an individual sports journalist and animate a fledgling career in sports journalism may, perhaps unavoidably, be limited (and even compromised) when it comes to advising on coverage of socially and ethically sensitive matters. 'Breaking in' to the highly competitive sphere of sports journalism means an element of conformity, of 'fitting in' with customs, norms and attitudes that have crystallized over the longee duree. And there is evidence to suggest that even once graduates find their places among the journalistic fraternity, what is learned on the job takes precedence over the learnings of more formal curricula (Frith and Meech, 2007).

With this concern in mind, Farrington et al. (2012) position their Race, Racism and Sports Journalism as a response to other books in our sample, referring directly to those 'practical guides to sports journalism that offer functional advice on techniques such as match reporting and sourcing' (p. 3). As indicated by their shared inclusion in our sam- ple, our view is that books like Farrington 
et al.'s that closely consider coverage of sport- related societal issues are not so different from books designed first and foremost to be practical guides, like Gisondi's Field Guide to Covering Sports. Our point here is that authors of all of the examined texts have their say on matters of ethics and social issues, albeit with differing emphasis and differing amounts of coverage explicitly afforded to those matters. Yet, Farrington et al.'s book does differ in a few crucial areas, not least in its foregrounding of ethics in the introduction by way of critique.

Specifically, Race, Racism and Sports Journalism scrutinizes the guidelines on report- ing about 'race' set out in the UK Press Complaints Commission. These guidelines, which largely echo the content and structure of other ethical Codes reproduced through- out our sample, state the following:

1) The press must avoid prejudicial or pejorative reference to an individual's race, colour, religion, sexual orientation, physical or mental illness or disability.

2) Details of an individual's race, colour, religion, sexual orientation, physical or mental illness must be avoided unless genuinely relevant to the story. (Cited in Farrington et al., 2012: 4)

The authors take issue with the stipulation that an 'individual's race, colour...' or other marker of identity is highlighted, but not reference to groups, regions or nations. That racism often operates at the level of group homogenization and stigma, such as in jingoistic and xenophobic coverage of major sports events, makes this a crucial and problematic omission.

With the critique of policy as a starting point, the authors then turn to theories of 'race' developed in cultural studies and related fields to illustrate the limits of individualized statements on how prejudice, and racism in particular, operate. They show how ideas about race saturate everyday life through institutions, including media. They illustrate how scholars in media and cultural studies have shown 'race' to be a myth insofar as it designates any relation between one's skin colour or appearance and generalized traits or capacities - a myth, nonetheless, that 'exists as a conceptual reality' (Farrington et al., 2012: 12) that structures how many people see the world. They similarly demonstrate the crucial role of media in reproducing the concept of 'race', which cannot be divorced from the problem of racism.

There is much to commend in this approach to discussing a key social and societal issue pertaining to sports journalism - an approach that weaves cultural theory into the problems of sports media to produce a decisive critique that, paradoxically, makes jour- nalists more and less responsible for their coverage. On one hand, journalists are more responsible precisely because they are of course in privileged positions from which to circulate or interrupt assumptions about and representations of 
'race'. Yet, on the other hand, they are not - as many scholars concerned with how racism operates might con- tend - necessarily 'guilty' of intentional racism in coverage that is nonetheless racist (see Eduardo Bonilla-Silva's Racism without Racists (2006) for an account of how racism has come to operate through forms that are not explicitly racist and the label 'racist' rejected overwhelmingly by those who nonetheless perpetuate racism).

It is worth noting here that Farrington et al.'s book emerged from a collaboration between a sports journalist with 18years of experience turned senior lecturer in sports journalism (Farrington), a PhD candidate in media and cultural studies (Kilvington), the sports journalism programme leader at the University of Sunderland (Price) and the programme leader for media, culture and communication (Saeed). The exceptionalism that often characterizes relations between sport, journalism and scholarship is challenged through this shared authorship and the argument that emerges is, we would suggest, all the stronger for it. That said, the book is still not a blueprint on how to do journalism better: how to rise to the challenge of not only avoiding problematic reference to this or that phenomena but also producing coverage that takes a more active stance against these societal ills in which sport and media are implicated. Nor does it take up the question of how one might produce such coverage under the current, fast-changing conditions of work in news media industries.

\section{Discussion: Towards 'strong objectivity' in sports journalism}

There are no standards or rules as to what qualify as 'valid' sports media opinions. Validity is usually measured by ratings or circulation, not quality. Who can define a quality opinion anyway? (Schultz, 2005: 24)

Brad Schultz, author of Sports Media: Reporting, Producing, Planning (2005), is correct in intimating that there is no present consensus in sports journalism - nor journalism at large for that matter - as to what constitutes quality. However, the attempt to take up the question of quality seems imperative if the aim is to address the array of criticisms con- tinually levelled at sports journalism as practice and industry. Such an attempt is surely in keeping with the professionalization of sports journalism that is evidenced by the publication of textbooks such as Schultz's and the rest of the books considered in this study. How are we to evaluate our findings, then, without an authority on journalistic excellence from the newsroom or the classroom? What arbiter might help to define a 'quality opinion?'

We might first revisit the contentions of those who are currently leading scholarly debates regarding journalistic quality. Shapiro et al. (2006) sought out the ranking crite- ria used by judges for 
journalistic awards programmes in Canada, but found no standard agreement on what 'excellent' reporting was or should be. In a subsequent exploration of the question of quality journalism, Shapiro identified the following passage - from Bogart (2004) - as capturing the criteria usually used to invoke excellence:

When experienced news people are asked what makes for quality, a number of words and phrases inevitably surface: integrity, fairness, balance, accuracy, comprehensiveness, diligence of discovery, authority, breadth of coverage, variety of content, reflection of the entire home community, vivid writing, attractive makeup, packaging or appearance, and easy navigability. (p. 40, quoted in Shapiro, 2010: 148)

Shapiro (2010) supplements Bogart's list of criteria by identifying 'benefit to society' as a characteristic of quality journalism (p. 148).

In our study, we were guided to some degree not only by the work of Shapiro and oth- ers who have debated journalistic quality in recent years (Lewis, 2014; McChesney, 2013; Post, 2015) but also by a broader curiosity as to how excellence is invoked, implied and evidenced in sports journalism textbooks. One of our central findings and conten- tions is that there is, to say the least, room for improvement in sports journalism text- books when it comes to advising on how to broach social issues. The issues that emerged from our analysis on this front are not insignificant. Consider, for example, the implica- tions of placing references to the problems with racist, sexist, ableist and nationalistic reporting in appendices of textbooks, as an afterthought - and suggesting only, as a remedy to these problems, that would-be journalists not produce writing that is racist, sexist and so forth. Consider also the implications of suggesting that social commentary is a 'dangerous area' that is best avoided by sports reporters. In our view, it is difficult to avoid concluding that in downplaying the importance of engaging in an informed and focused manner with sport-related social issues - as a marker of doing excellent journal- istic work - and in offering little tangible advice as to how such work could be done, many textbooks are not helping to equip sports journalists with techniques to adequately deal with such issues, or do justice to why they are important, or explain how they mani- fest in sports and are reproduced through sports media. Revisiting Shapiro's (2010) cri- teria, the 'benefits to society' (p. 148) of journalism are clearly inhibited if the relationship between sport and society, and of sports journalism and social issues, is not recognized and treated carefully by journalists.

More complicated is the reference to objectivity: a prominent theme across all of the sampled textbooks. As Post (2015) recently illustrated based on survey data drawn from Germany, while 
'journalists and academics appreciate objectivity to a similar degree' (p. 743), the former do not necessarily subscribe to or take up the scientific definition of objectivity. An explanation offered for this discrepancy, drawn from Walter Lippmann's contributions to debates about journalism's mission and purpose, is 'that scientists deal with repetitive, foreseeable occurrences aiming at discovering regularities, whereas jour- nalists deal with singular occurrences aiming at giving timely cross-cut sections of day- to-day affairs' (p. 733). It is important to note at this juncture that Post's definition, inherited from Karl Popper's philosophy of science, is not the only way that scientists, or those who study science, have conceptualized objectivity (see Ward, 2004). The most renowned alternative is Thomas Kuhn's (1962) work on the structure of scientific revo- lutions, in which he shows how paradigmatic shifts in knowledge emerge from irregu- larities in understandings of the world that play out as much in the culture of scientific practice as in its objects of inquiry. More recent contributions from the field of science studies have continued to develop this line of argument through studies of scientific practice - in laboratories (Latour and Woolger, 1979; Myers, 2015) and hospitals (Mol, 2002), as well as in more everyday scenes - in which involvement and passion are always at play and the emergent knowledge of the world no less consequential or 'beneficial to society' for it.

Several critical insights emerge from this sketch of objectivity, which fold back onto sports journalism and scholarship about its practice. One, to reiterate, is that the authors of these textbooks mostly adhere to a narrow understanding of objectivity insofar as it is understood as a dispassionate, detached position from which to report about on-field affairs. Reference to balance, fairness, impartiality and other terms gathered under this notion of objectivity resonates with a 19th-century understanding of scientific method that has been contested from various vantage points throughout the 20th and into the 21st centuries. These terms also do little to assuage concerns about how sports journalists cover social issues insofar as they are limited to the internal logics of sporting contests. Indeed, as noted earlier, it seems that recourse to objectivity in these textbooks 'has more to do with attempts to boost the status of the claim than with any actual criteria the claim has satisfied' (Harding, 2015: ix). In the case of sports journalism textbooks, this creden- tializing technique is as much about professionalizing sports journalism as it is about the 'objectivity' of journalistic renderings of sport. Certainly those who study sports media, and surely a proportion of those who consume it, would contend that detached, unbiased reporting about 'what happened in the game' is not the most important criteria for excel- lent sports journalism - although partisanship of different kinds is often associated with its problems.

However, we need not altogether throw out objectivity as a principle or arbiter of excellent sports journalism. Stephen Ward (2004) comes to this same conclusion at the end of his own exegesis on 
the role of objectivity in 400 years of journalism and finds some middle ground between universalism and relativism in his proposal for a 'prag- matic objectivity' for journalists to heed. Ward (2004) is concerned that the impossibility of a 'truly' objective journalism might lead to an ethically bankrupt relativism, in which the democratic functions of reporting become available to any sort of interest, unhinging media from civic responsibility. While the naively staunch notion of objectivity, in which experience cannot enter the fray at all for something to be considered a fact, has been wounded by critiques from many quarters, including within journalism, the critique of the possibility of an objective journalism won't do either. For 'journalists continue to need a clear, vigorous norm of objectivity to guide their practice' and Ward puts forward his version as a 'holistic, fallible, rational evaluation' by comparison (p. 300).

Ward's middle ground, despite its philosophical scope, does not seem to offer solu- tions to the limitations we have identified in the focal textbooks. Instead, we point to the notion of 'strong objectivity' that has developed in feminist science studies since the 1970s. Sandra Harding (2015) brings together several decades of research to show how factual and robust knowledge and 'prodemocratic transformations of the social order' (Harding, 2015: xiii) can not only be reconciled but have co-produced each other throughout the history of modern science. Hence, her concept of 'strong objectivity', the premise of which is that

starting research from 'outside' a discipline can enable the detection of the dominant values, interests, and assumptions that may or may not be widely prevalent, but which tend to serve primarily the most powerful groups. (p. 34)

The principle that Harding is advocating is also a principle that journalism holds dear, as journalists themselves are often considered to be the 'outside' that is needed for hold- ing other social groups and institutions accountable. But what of the 'dominant values, interests and assumptions' of journalism itself, in this case sports journalism? Strong objectivity highlights how journalism can itself be productively informed by 'outside' groups, not as external overseers or regulators but as coproducers of quality reporting. It is by this measure that we might qualify the quality of Farrington et al.'s book Race, Racism and Sports Journalism as a collaboration featuring different outsides, scholarly and otherwise. Likewise, in Rob Steen's book, it was the historical and geopolitical diversity of reporting about FIFA's former president Sepp Blatter's sexist comments that made that reporting favourably comparable (albeit without any outline of the specific criteria for this comparison). Here, we find diversity enriching objectivity: making journalism stronger, more robust and more broadly informed all at once. And yet that diversity is only relative; the authorship of our sample is overwhelmingly male, with Kathryn Stofer (co-author of Sports Journalism: An 
Introduction to Reporting and Writing) the only exception.

This leads neatly to a related problem facing sports journalism - a problem that has been identified within sports media research and elsewhere (Apostolis and Giles, 2011; Sabo et al., 1996): a distinct lack of diversity among reporters. For example, in a study of how US sports media represented head trauma and concussion instances, Anderson and Kian (2012) cited a survey of 320 newspapers and sport Web sites undertaken by Lapchick et al. (2011). The survey found that men comprise 94 percent of sports editors, 90 percent of assistant sports editors, 89 percent of reporters, 90 percent of columnists and 84 percent of copy editors/designers in the United States. The question then arises: 'What kind of objectivity emerges or can emerge from such a homogeneous labour force?' The question is rendered even more pressing given the amount of scholarship that is critical of how gender is represented in sports media. Relevant again is Hardin et al.'s (2006) study of sports journalism textbooks, which analysed the citations of male authors, references to male athletes and journalists, and the representation of men and women in text and photographs. These authors concluded that the textbooks they studied 'reinforce the idea that sports and sports journalism are masculine: they are enterprises for men' (p. 441). Our study asked a different question of a more recent sample of textbooks, but there is clearly common ground in our contentions: the need for change in what has become habitual and even surreptitiously reinforced in sports journalism.

\section{Conclusion}

We conclude by restating the most striking finding from our study of sports journalism textbooks: that sports journalism students interested in learning about how to report on sport-related social issues would be hard pressed to find nuanced information or advice in the sports journalism textbooks we studied, with some notable exceptions. We came to this overarching finding from a number of directions. For example, we found that discus- sions of ethics pertaining to sports journalism - recognizing that socially responsible coverage and coverage of social issues were generally deemed ethical issues - were most often placed near the end or in the appendices of the textbooks we studied, and that these appendices commonly included vague and superficial directives for sports journalists. Perhaps more disconcerting is that authors of some texts seemed to avoid or neglect discussions about how to cover contentious sport-related social issues, or suggested that sports journalists sidestep what might be considered controversial or sensitive topics altogether. We similarly observed that a narrow understanding of 'objectivity' was fore- grounded in discussions of what counts as 'quality' journalism - with most authors focusing on the need to 'not take sides' when covering games. There was little discussion of how the question of objectivity might be relevant to attempts by sports journalists to 


\section{Journalism 00(0)}

address complex sport-related issues and debates (e.g. about performance-enhancing drug use, or corruption, or gender issues in sport) or much in the way of reflexive commentary about how journalists, individually and collectively, are part of the coverage they produce.

Somewhat mitigating these findings, perhaps, is the possibility that practical advice for gaining entry to the sports newsroom might well involve 'avoiding sensitive topics'. If agenda setters in the sports journalism profession - that is, leaders in the newsrooms where decisions about what to report and how to report are commonly made - are not promoting and/or valuing nuanced coverage of social issues, then those with extended experience in and knowledge of sports journalism who author textbooks might see such advice as being pertinent and useful in a practical (i.e. career-oriented) sense. This point goes some way to addressing the question of 'why' some authors of these texts say little about socially responsible coverage and about the complexities of covering social issues related to sport. Insofar as that is the case, this observation would seem to act as a deeply troubling commentary on at least some strands of sports journalism and newsroom cultures.

This final point takes us to the edge of what can be claimed in this article since our study is based only on sports journalism textbooks, and not on how they are taken up, or on how social issues are understood by agenda setters in the sports journalism profession. Future research could prudently track how sports journalism textbooks are taught in classrooms and how these books and their advocations are (or are not) taken up by practicing journalists (following Frith and Meech, 2007). Such studies could also use- fully extend to an analysis of how links between academic training and journalistic practice may be evolving over time, as qualifications for successful entrée into sports journalism increasingly include formal training in journalism schools.

Finally, we reiterate our call for 'strong objectivity' in sports journalism as an alternative to the usual deployment of objectivity in the textbooks we studied - recognizing that objectivity, as described in the textbooks, mostly encapsulated the conscious stifling of one's investment in a sporting contest in order to present a professional veneer. In the model of 'strong objectivity' (Harding, 2015) we are borrowing and redeploying, objectivity is not only extended beyond the sporting contest to incorporate the roles and responsibilities of the industry and its professionals, but it also makes the issue of homogeneity in the newsroom a matter of quality assurance. Put another way, adopting strong objectivity as an evaluative lens would allow one to recognize that in order to be able to scrutinize sports culture in a manner befitting a profession, sports journalism has to differentiate 
itself from that culture. Doing so might seem far from desirable, as the most frequent complaint of sports reporters of the 21 st century, besides the multimedia demands of their rapidly changing industry, is that it is ever more difficult to secure meaningful contact with professional athletes. What is the chance of doing so when the journalist is known to frequent the 'dangerous' arena of social commentary? Heavy criticism surely lightens one's contacts book. Here, we would only encourage all those invested in (the future of) sports journalism - scholars and practitioners alike to recognize the stakes of such manoeuvres and ask questions accordingly. Could sports journal- ism (and its educative forms) in the future inherit more from the idealist's vision of journalism as a democratic project intended for the betterment of society, than from the allure and prestige of covering sports? Just as Farrington et al. (2012) foregrounded

policy concerning 'race' and racism in their study of sports journalism, might sports journalism itself place the social, cultural and political significance of sport at the centre of ongoing attempts to define quality?

It might of course be the case that what we are proposing is already a cornerstone of sports journalism programmes across and beyond the UK and North America, and that the textbooks and their authors are simply out of touch with these developments. In which case, the absence of such discussions in our sample and from public and scholarly records elsewhere would underscore the need for greater dialogue between the study and the practice of sports journalism. Either way, we acknowledge the difficulties associated with implementing any notion of strong objectivity in sports journalism at present, given all we know about the predilection for practical knowledge habituated through the sports news beat (not to mention the compounding of this tendency towards practicality by the economic pressures to prioritize speed and popularity in the fluctuating political econ- omy of media industries). The idea of implementing concepts 'from without' also jars starkly with the kinds of exceptionalism discussed earlier in this essay, and is not conducive to the coproduction of knowledge that 'strong objectivity' encourages.

In the end, we suggest that the education of would-be sports journalists in university programmes does hold some promise for such coproduction. That our sample of texts also included some excellent, albeit extraordinary, sections where sport-related social and societal issues and debates were foregrounded and addressed with both journalistic practice and sociological rigor in mind is relevant here, especially if we note the often diverse academic and journalistic backgrounds of those who collaborated on these particular texts. Such a finding is reflective of the fact that sports journalism programmes at universities are already a space where the newsroom and the classroom 
commingle, and while the evidence collated by Frith and Meech (2007) suggests that the student acquiesces to the culture of the work place, there is no need to concede that this relation remains static in an industry undergoing such great change.

\section{Declaration of Conflicting Interests}

The author(s) declared no potential conflicts of interest with respect to the research, authorship, and/or publication of this article.

\section{Funding}

The author(s) disclosed receipt of the following financial support for the research, authorship, and/ or publication of this article: The research was funded through a Social Sciences and Humanities Research Council of Canada Insight Grant (IG \#435-2012-1234).

\section{References}

Anderson, E., \& Kian, E. (2012). Examining Media Contestation of Masculinity and Head Trauma in the National Football League. Men \& Masculinities, 15, 152-173.

Andrews DL and Giardina MD (2008) Sport without guarantees: Towards a cultural studies that matters. Cultural Studies <=> Critical Methodologies 8: 395-422.

Andrews P (2015) Sports Journalism: A Practical Introduction, 2nd edn. London: SAGE. Apostolis N and Giles AR (2011) Portrayals of women golfers in the 2008 issues of Golf Digest. Sociology of Sport Journal 28(2): 226-238.

Bogart L (2004) Reflections on content quality in newspapers. Newspaper Research Journal 25(1): 40-53.

Bonilla-Silva E (2006) Racism without Racists: Color-Blind Racism and the Persistence of Racial Inequality in Contemporary America. Lanham, MD: Rowman \& Littlefield Publishing.

Boyle R (2006) Sports Journalism: Context and Issues. London: SAGE. Braun V and Clarke V (2006) Using thematic analysis in psychology. Qualitative Research in Psychology 3(2): 77-101.

Bryman, A. (2012). Social Research Methods. New York: Oxford University Press.

Cooky C, Messner M and Musto M (2015) 'It's dude time!' A quarter century of excluding women's sports in televised news and highlights shows. Communication \& Sport 3(3): 261-287. 
Croteau D and Hoynes D (2003) Media Society: Industries, Images, and Audiences, 3rd edn. Thousand Oaks, CA: Pine Forge.

Donnelly P (2011) Taking Sport Seriously: Social Issues in Canadian Sport. Toronto, ON, Canada: Thompson Educational.

Farrington N, Kilvington D, Price J, et al. (2012) Race, Racism and Sports Journalism. London: Routledge.

Fink CC (1995) Sportswriting: The Lively Game. Ames, IA: Iowa State University Press.

Fisher P and Peak S (eds) (1998) The Media Guide. London: Fourth Estate.

Frith S and Meech P (2007) Becoming a journalist journalism education and journalism culture. Journalism 8(2): 137-164.

Garrison B (1993) Sports Reporting. Ames, IA: Iowa State University Press. Gisondi J (2011) Field Guide to Covering Sports. Washington, DC: CQ Press.

Hardin B and Hardin M (2004) Distorted pictures: Images of disability in physical education textbooks. Adapted Physical Activity Quarterly 21: 399-413.

Hardin M, Dodd J and Lauffer K (2006) Passing it on: The reinforcement of male hegemony in sports journalism textbooks. Mass Communication and Society 9(4): 429-446.

Harding S (2015) Objectivity and Diversity: Another Logic of Scientific Research. Chicago, IL: University of Chicago Press.

Hartley J (1996) Popular Reality: Journalism, Modernity, Popular Culture. London: Arnold.

Howe PD (2008) From inside the newsroom: Paralympic media and the 'production' of elite disability. International Review for the Sociology of Sport 43(2): 135-150.

Jhally S (1984) The spectacle of accumulation: Material and cultural factors in the evolution of the sports/media complex. The Insurgent Sociologist 12(3): 41-52.

Kuhn TS (1962) The Structure of Scientific Revolutions. Chicago, IL: University of Chicago Press.

Lapchick RA, Moss A II, Russell C, et al. (2011) The 2010-11 Associated Press Sports Editors racial and gender report card. Report, Institute for Diversity and Ethics in Sport, University of Central Florida. Available at: https://nebula.wsimg.com/b280bacae8b4469f3a2ec2c42dd 
65f4f?AccessKeyId=DAC3A56D8FB782449D2A\&disposition=0\&alloworigin=1 (accessed 7 July 2017).

Latour B and Woolger S (1979) Laboratory Life: The Social Construction of Scientific Facts. Beverly Hills, CA: SAGE.

Lewis J (2014) Beyond Consumer Capitalism: Media and the Limits to Imagination. Malden, MA: Polity Press.

Lippmann W (1922) Public Opinion. New York: Harcourt, Brace and Company.

Lynch J and McGoldrick A (2005) Peace Journalism. Gloucestershire: Hawthorn Press.

McChesney RW (2013) Digital Disconnect: How Capitalism Is Turning the Internet against Democracy. New York: The New Press.

Maguire J, Poulton E and Possamai C (1999) Weltkreig III? Media coverage of England versus Germany in Euro 96. Journal of Sport \& Social Issues 23(4): 439-454.

Mol AM (2002) The Body Multiple: Ontology in Medical Practice. Durham, NC: Duke University Press.

Myers N (2015) Rendering Life Molecular: Models, Modelers, and Excitable Matter. Durham, NC: Duke University Press.

Pederson PM, Whisenant WA and Schneider RG (2003) Using a content analysis to examine the gendering of sports newspaper personnel and their coverage. Journal of Sports Management 17: 376-393.

Pike E (2011) The active ageing agenda: Old folk devils and a new moral panic. Sociology of Sport Journal 28(2): 209-225.

Post S (2015) Scientific objectivity in journalism? How journalists and academics define objectiv- ity, assess its attainability, and rate its desirability. Journalism 16(6): 730-749.

Reinardy S and Wanta W (2015) The Essentials of Sports Reporting and Writing. New York: Routledge.

Romano AR (2010) Deliberative journalism: American public journalism versus other international models. In: Romano A (ed.) International Journalism and Democracy: Civic Engagement Models from around the World. New York: Routledge, pp. 16-32.

Rosen J (2001) What Are Journalists For? New Haven, CT: Yale University Press. Rowe D (2007) Sports journalism still the toy department of the news media? Journalism 8(4): 385-405. 
Sabo D, Jansen SC, Tate D, et al. (1996) Televising international sport: Race, ethnicity, and nationalistic bias. Journal of Sport \& Social Issues 20(1): 7-21.

Schultz B (2005) Sports Media: Planning, Production, and Reporting. Oxford: Elsevier.

Shapiro I (2010) Evaluating journalism: Towards an assessment framework for the practice of journalism. Journalism Practice 4(2): 143-162.

Shapiro I, Albanese P and Doyle L (2006) What makes journalism 'excellent'? Criteria identified by judges in two leading awards programs. Canadian Journal of Communication 31(2): 425-445.

Silk M (2012) The Cultural Politics of Post-9/11 American Sport: Power, Pedagogy and the Popular. London: Routledge.

Steen R (2015) Sports Journalism: A Multimedia Primer. 2nd edn. London: Taylor \& Francis.

Stofer KT, Schaffer JR and Rosenthal BA (2010) Sports Journalism: An Introduction to Reporting and Writing. Plymouth: Rowman \& Littlefield Publishing.

Thompson HS (1973) Fear and loathing at the Superbowl: No rest for the Wretched. Rolling Stone, 128. Available at: http://www.rollingstone.com/culture/news/fear-and-loathing-at-the-super-bowl-no-rest-for-thewretched-19730215

Thussu D (2000) International Communication: Continuity and Change. London: Arnold.

Tomlinson A (1999) The Game's up: Essays in the Cultural Analysis of Sport, Leisure and Popular Culture. Aldershot: Ashgate.

Tomlinson A (2005) Sport and Leisure Cultures. Minneapolis, MN: University of Minnesota Press.

Toney J (2013) Sports Journalism: The Inside Track. London: Bloomsbury.

Ward S (2004) The Invention of Journalism Ethics. Montreal \& Kingston: McGill-Queen's University Press.

Weedon, G., Wilson, B., Yoon, L. Lawson, S. (2016). Where's all the 'Good' Sports Journalism?: Sports Media Research, the Sociology of Sport, and the Question of Quality Sports Reporting. International Review for the Sociology of Sport. Published 'Online First', DOI: 10.1177/1012690216679835.

Wilson, B. (1997). "Good Blacks" and "Bad Blacks": Media Constructions of African-American Athletes in 
Canadian Basketball. International Review for the Sociology of Sport, 32(2), 177-189. 